Rev. Latinoam. Psicopat. Fund., São Paulo, v. 11, n. 4, p. 696-701, dezembro 2008

Gianfrancesco, Angelo. "Monachisme ancient et psychopathologie” L'Évolution Psychiatrique, v. 73, n. 1, p. 105-126, January-March 2008. Kölbel, Max. “'True' as ambiguous” Philosophy and Phenomenological Research, v. 77, n. 2, p. 359-384, September 2008. Rayo, Agustín. "Vague representation" Mind, v. 117, n. 466, p. 329-373, April 2008. Stein, George. "Lost in translation: the biblical classification of personality disorder"

The British Journal of Psychiatry, v. 193, n. 4, p. 337, October 2008.

\title{
"Lost in translation"
}

Para aqueles que ainda insistem em ler - teimosamente, com curiosidade renovada, pacientemente, com voracidade e veracidade sustentadas - após tantos anos de fluxo e refluxo deste hábito renitente, restará uma tarefa que a alguns resultará incômoda ou inglória: a de inventar, selecionar e hierarquizar um plano pessoal de leituras. E, porque não, julgando pertinente, subvertê-lo, modificar um pouco o itinerário original e, quando tanto, perder-se um pouco pelo caminho.

É uma tarefa bem solitária, e não é de todo mal que seja assim. É, em contradição com a solidão, uma tarefa que supõe pôr-se em conversação com outros solitários. Supondo que essa seção de "Resenha de Artigos” possa prestar- 
se a tal diálogo, percamo-nos um pouco por alguns textos de revistas bem representativas do que se produz de relevante no campo de interseção entre a psicopatologia e a filosofia.

No The British Journal of Psychiatry, há uma interessante coluna chamada "Psychiatry in the Old Testment", regularmente publicada nesse periódico e assinada por George Stein. Como o nome da coluna sugere, seu autor estabelece o que, aqui, poderíamos chamar de "ligações perigosas" entre, de um lado, certos personagens ou caracterizações presentes no Velho Testamento e, de outro, elementos - sinais, sintomas, síndromes e categorias nosológicas - da psiquiatria; habitualmente apresentadas em terminologia psicopatológica e segundo as classificações contemporâneas. Na edição de outubro, por exemplo, Stein resgata do Livro dos provérbios, a figura do "tolo", para revelar o quanto a tradução canônica da edição inglesa do Velho Testamento planificou e resumiu certas riquezas polissêmicas do texto hebreu. Escreve ele:

O Livro dos provérbios alerta quanto ao melhor caminho para se chegar a uma vida plena e a um padrão alto de moralidade pessoal. Aqueles que conseguem alcançá-lo são chamados "os sábios", os que são virtuosos; mas aqueles que não o conseguem são "os tolos”, que são maus. O interesse psiquiátrico recai sobre os últimos. Infelizmente, a palavra "tolo" na versão St. James (assim como em edições posteriores) foi utilizada na tradução inglesa para oito palavras distintas em hebreu, cada qual descrevendo personalidades distintas. Nesse sentido, a tipologia de personalidades do hebraico antigo foi efetivamente perdida na tradução.

A questão é que, do nosso ponto de vista, Stein é capturado pela mesma armadilha que, em algum momento, ele pretendeu denunciar. Ao lamentar, em sua análise da tradução inglesa, a simplificação da variedade de matizes presentes no original, parece esquecer-se de que, se de fato algo se perde necessariamente em uma tradução, tantas outras coisas se ganham ou se acrescentam. Cada palavra, é certo, tem o seu próprio espectro associativo e semântico; e cada época modifica um pouco - ou muito - tais espectros. O surgimento e a solidificação de certos saberes - como foi o caso da psiquiatria e da psicologia no final do século XVIII e início do século XIX - imprimem subtrações e acréscimos determinantes na acepção e uso de determinados vocábulos, dentre o quais "loucura", que talvez seja apenas o exemplo mais pungente das transformações de um conceito para estes campos específicos do saber. Dentro dos 200 anos que transcorreram de lá para cá, muitas outras modificações - grosso modo refletidas nas muitas classificações das habitualmente numerosas edições dos tratados de psiquiatria foram acrescidas, eventualmente torcendo enormemente o significado "de origem” de um determinado vocábulo. Se em 200 anos de psiquiatria perdeu-se e 
ganhou-se tanto, pode-se imaginar a epopéia vivida por certos termos bíblicos nos últimos milênios!

Portanto, não se trata apenas de um equívoco, ou de uma simplificação de tradução, mas da viagem transfiguradora dos termos ao longo da história de seu uso lingüístico. Assim, o que Stein oferece com uma mão - a recuperação das oito palavras hebraicas e, com elas, a restituição de uma certa riqueza de significados - ele toma com a outra ao sugerir a fixação de cada uma das oito palavras em categorias presentes no conjunto de transtornos de personalidade da DSM, ou pelo menos em referências nosológicas contemporâneas:

As principais classes para o tolo, em hebreu são: kesil (literalmente, estúpido e superconfiante), uma pessoa pouco inteligente, freqüentemente envolvida em brigas; ewil, um indivíduo moralmente obtuso, mas mais inteligente que kesil; pethi, um simplório, talvez com incapacidade intelectual, que não é capaz de planejar o futuro; o hasar-leb (literalmente, descentrado), também de pouca inteligência, que negligencia a si mesmo e a sua propriedade. Outras personalidades são ocasionalmente também mencionadas: $b a-a r$, um indivíduo rude; nabal, um homem depravado e bruto (a palavra nabal também significa odre, sugerindo um vínculo com o alcoolismo); holel, um louco irracional; les, também traduzido como zombeteiro, um indivíduo narcisicamente insolente, enquanto belial (um vigarista) designa um psicopata agressivo, que mostra muitas das características do transtorno de personalidade antisocial do DSM-IV. Finalmente, uma personalidade feminina, essa-zarah, a mulher não convencional ou livre, uma pessoa ruidosa e rebelde, sempre ativa, de relacionamentos numerosos, reveladora tanto de características histriônicas quanto de características limítrofes.

Um assunto leva a outro, e desse primeiro artigo somos levados a dois outros que, de modo convergente, iluminam duas discussões implícitas ao interesse pela renovação do uso lingüístico de determinadas expressões. Um deles - "True as ambiguous”, publicado na edição de setembro da Philosophy and Phenomenological Research - apresenta a eventual ambigüidade com que todos nós, falantes competentes da língua, nos referimos ao valor de verdade de determinada assertiva ou definição conceitual. Isto é, embora sejamos capazes de uma certa crítica epistemológica dirigida à idéia de uma suposta "verdade" de caráter essencialista, somos "flagrados", com uma freqüência incômoda, a utilizar conceitos psicopatológicos e categorias classificatórias com ares de verdades absoluta. A discussão, naturalmente, mereceria mais espaço para que pudesse acontecer de modo suficientemente nuançado; entre outras razões porque nada impede que ambas as posições - contraditórias à primeira vista - possam ser sustentadas de modo harmônico. É que nada impede que se possa fazer, em relação a certas palavras, escolhas semânticas "firmes", aliando o uso lingüístico à pers- 
pectiva mais teórica de que os usos são sempre filiados ao seu tempo e que a revisão de posições anteriormente adotadas não deve ser constrangida pela fixidez de significados, ou pela perspectiva errônea de que, se mudamos a definição de determinado conceito é porque estaríamos necessariamente abandonando uma perspectiva mais tosca em direção a uma outra, mais próxima de como as coisas afinal seriam "na realidade”. Quando, é claro, estamos apenas viajando no tempo.

O outro artigo - "Vague representation", publicado na prestigiosa Mind segue a mesma linha de investigação epistemológica, destacando-se pelo rigor com que a discussão é conduzida. Fundamentalmente, seu autor - Agustín Rayo, do Department of Linguistics and Philosophy do MIT - parte da idéia de que o uso lingüístico sempre admite certa vagüidade de significado, mas critica a adesão festiva a essa idéia, cobrando e contribuindo com a fundamentação conceitual dessa posição teórica. Rayo não desconhece o risco que se corre na relativização pouco refletida do valor de verdade dos termos lingüísticos. Afinal, uma coisa é admitir a inexistência de "uma verdade" em relação a qual devamos medir os nossos conceitos; outra coisa é negligenciar o estudo sério do percurso histórico e a pesquisa responsável do peso semântico dos termos da língua.

As discussões presentes nestes dois últimos artigos, não estão presentes por acaso em revistas cujos conteúdos incluem à larga temas da psicopatologia. Psiquiatras, psicólogos, psicanalistas e trabalhadores da saúde mental ganhariam enormemente caso, vez ou outra, se debruçassem sobre as bases (filosóficas sim!) das teorias e práticas sobre as quais as suas ações profissionais repousam. Talvez não pareça óbvia a um psiquiatra, a necessidade de dividir o seu tempo de leituras e de reflexão entre o livro de psicofarmacologia e o de psicopatologia filosófica; é provável que, ao ler artigos como os apresentados nesta seção da $R e-$ vista Latinoamericana de Psicopatologia Fundamental, ele se sinta sempre meio roubado em suas leituras mais técnicas. Mas não se inquietar em relação ao contexto histórico do qual brotaram as concepções que ele eventualmente adota sem muita crítica, é fazer de um potencial clínico reflexivo, um psiquiatra domesticado, apenas mais um, integrante ingênuo de um numeroso rebanho de poucos e rígidos pastores.

Concluiremos com um artigo publicado na L'Évolution Psychiatrique, no qual também está presente a intenção de resgate de uma expressão antiga curatio verbi - convocando, portanto, e mais uma vez, a nossa habilidade do que poderia ser chamada uma "tradução reflexiva". Neste ponto, a pergunta fundamental parece ser: O que seria, nesse caso, não "perder-se na tradução”?

Se não, vejamos, a expressão De curatio verbi, que poderia, sem muito dano, ser traduzida por “a cura pela palavra”, pode ser encontrada originalmente em 
João Cassiano (360-435), embora remonte não apenas à literatura monástica cristã dos séculos IV e V, mas toda uma tradição filosófica que começaria em Sócrates e nos diálogos platônicos. Então, temos uma expressão com uma história tão ou mais longa do que a do próprio Cristianismo; resgatar em tradução ou em análise o seu sentido original é tarefa fadada à auto-ilusão. Como transportá-la aos dias atuais, conservando o seu interesse e a sua eventual pertinência para o estudo da psicopatologia?

Segundo Gianfrancesco, autor do artigo, "curar pela palavra remete a duas atividades monásticas essenciais: dizer-se e receber sentido”. A primeira atividade implica "manifestar os pensamentos a um outro" - todos os pensamentos, ou ao menos aqueles que surgem "como um prurido". O "outro" que receberia tais pensamentos - normalmente um monge mais experiente (uma espécie de "pai espiritual” ou de “diretor de consciência”) - é alguém encarnado, mas também, e no limite, um outro maior: "Deus”. E como que antecipando uma possível (e provável) fixidez interpretativa, Gianfrancesco se apressa em recusar a analogia entre esse segmento da vida monástica e suas práticas e o set analítico a livre associação; entre outras razões, porque os pensamentos ditos não são espontâneos, mas objeto de uma triagem prévia e reflexiva por parte do monge que os experimenta. Com essa recusa em aproximar os séculos, ganhamos todos; caso contrário, o que obteríamos? Provavelmente algo leviano como: "os monges faziam uma proto-psicanálise”, ou pior, "estamos no caminho certo, os monges já faziam o que fazemos; e com bons resultados...”.

A segunda "atividade monástica essencial" - receber sentido de um outro também poderia ser presa fácil para pesquisadores e suas leituras aproximativas contemporâneas. Todavia, o "sentido" ofertado pelo monge que escuta, em nada se parece com uma interpretação psicanalítica: a entrevista entre monges correspondia a um evento absolutamente central na forma de vida de um monastério do século IV; disciplinava a semana, e não seria exagero dizer, organizava subjetivamente, num efeito para o qual a imagem de um espelho parece acertada:

A imagem especular (...) me designa e prova a minha existência singular (...). Eu diria que uma pessoa é uma fundação recíproca. (...) É isso que, depois de outros, Cassiano acrescenta; isso de que a dinâmica do espelho que personaliza não é um momento isolado da existência, mas que é para esses homens e mulheres do deserto uma modalidade de ser costumeira (...). A função terapêutica é cumprida aqui não mais pelo fato de dizer-se, mas por aquele de ser dito, pela dotação de sentido. Vemos no texto de Cassiano como ela opera. Sobretudo por um "posicionar a distância" do vivido por uns e por outros, de ambos os lados (da experiência). 


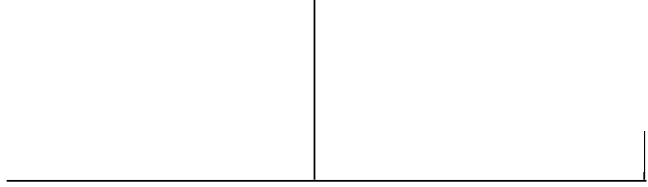

“Mas não é exatamente disso que se trata em psicanálise?”, perguntarão alguns. Não para os monges dos primeiros séculos do Cristianismo, responderia Cassiano.

Até a próxima edição!

\section{GUILHERME GuTMAN}

Psiquiatra e psicanalista; professor adjunto do Departamento de Psicologia da Pontifícia Universidade Católica do Rio de Janeiro - PUC-Rio (Rio de Janeiro, RJ, Brasil) Rua Visconde de Pirajá, 595/905 - Ipanema 22410-003 Rio de Janeiro, RJ.

Fone: (21) 3026-0064

e-mail: guilhermegutman@gmail.com 